\title{
Making sense of eating, weight and risk in the early teenage years: views and concerns of parents in poorer socio-economic circumstances
}

\begin{abstract}
This paper reports findings from a qualitative study which examined the perceptions and understandings underpinning the dietary practices in families with 'normal' weight and 'overweight' young teenagers living in poorer socio-economic circumstances. Thirty four parents/main food providers of boys and girls aged 13-14 years were interviewed. Within the home there was a strong acknowledgement of these early teenagers' own food preferences; parents also saw them as having increasing responsibility for their own food choices outwith the home but these were often described as 'not healthy' choices. However, parents saw dietary issues as of fairly low priority in the hierarchy of healthrelevant and other risks facing their teenagers. Equally, these interviewees felt that issues around body shape and size at this age were less potentially problematic than the risks to teenagers' mental or physical health of their becoming obsessed with weight loss. Parents often made sense of their teenager's body size and shape in terms of the variety of body types in families and inherited traits. Interviewees seemed to lack a discourse to understand weight and overweight in this age group, falling back on understandings derived from the adult lifestage. (Word count 188)

\section{Key words}

Teenagers, eating, weight, risk, socio-economic disadvantage

Full word count 8254 


\section{Making sense of eating, weight and risk in the early teenage years: views and concerns of parents in poorer socio-economic circumstances}

\section{Introduction}

Families are the primary setting for feeding children and young people, and for the establishment of patterns of food choice and consumption (Dietz, 2001). In the UK, however, relatively little is known about the socio-cultural processes and contexts framing these practices. For instance, the everyday negotiations between parents and their teenage children about what, where and how they eat remain under-explored (Murcott, 1987; Charles \& Kerr, 1988; Brannen, Dodd, Oakley, \& Storey, 1994). How parents and family background affect what teenagers eat is clearly complex. Survey data suggest that the influence of socio-economic status on dietary patterns remains strong, with less healthy eating associated with greater social deprivation (Shaw, McMunn, \& Field, 2000). Compared with the adult population, teenagers are also more likely to eat ‘unhealthy’ foods (Henderson, Gregory, \& Swann, 2002). However, relationships between early teenagers' dietary patterns and aspects of their family lives, such as family structure and maternal employment, are somewhat inconsistent (Sweeting \& West, 2005). Moreover, the ways in which parents may have an active influence over what their children and teenagers eat, and whether or not this promotes 'healthy' food choices, are not entirely clear. For instance, the popular view that certain eating practices and forms of commensality, such as family meals, are associated with healthier eating is not entirely 
borne out empirically in terms of similarity in food intakes between parents and children (Gillman, Rifas-Shiman, Frazier, Rockett, Camargo, Field, et al 2000; NeumarkSztainer, Hannan, Story, Croll, \& Perry, 2003). Furthermore, children and young people's attitudes towards food, nutrition and their eating patterns may differ from those of their parents (Le Bigot Macaux, 2001; Boutelle, Lytle, Murray, Birnbaum, \& Story, 2001). Also, despite exhibiting awareness of healthy eating messages the eating practices of many young teenagers do not reflect this knowledge (Inchley \& Currie, 2003), and what parents consider 'healthy' or 'balanced' may not always be in line with published guidelines for eating a healthy diet (Fuller, 2002).

In the UK, research into young people's eating behaviours has tended to focus on the problematical rather than the mundane, for example eating disorders (Frost, 2001) or 'unhealthy' patterns of consumption, such as skipping meals (Sweeting et al., 1994). Moreover, where the family context is concerned, such issues are often gendered and related to styles of parenting (see Dixey, Sahota, Atwal, \& Turner, 2001, for discussion). However, recent alarm about rising levels of obesity in the population as a whole has brought everyday food choice and eating behaviour in families to the fore as topics of general social and health concern. In particular, there has been a focus on obesity in adolescence as the proportion of overweight teenagers in the UK increases (McCarthy, Ellis, \& Cole, 2003) and this is considered to be a key risk factor for obesity and health risks in adulthood (Wright, Parker, Lamont, \& Craft, 2001). 
At present we know relatively little about how parents themselves view and interpret any risks attached to their teenagers' everyday food related practices and how they make sense of the body size and shape of their early teenage children. Rather, media and academic attention has tended to focus on other health relevant behaviours of teenagers, such as smoking, drug and alcohol misuse, unsafe sex, and the risks of their lifestyle choices in these areas (Backett-Milburn \& Mackinnon, 2003). Much theorising of risk and risk factors has relied heavily on the notion of the individual project (Giddens, 1991). Less attention has been paid to understanding how people assess risk in others (here, parents and their offspring) and how conceptualisations of risk are created and re-created in everyday practices and interactions (for example within families) as socially constructed realities (Green, 1997; Backett-Milburn \& Harden, 2004). This is a notable gap as the consumption of food and individual eating practices may often reflect, or are negotiated around, relationships between family members (Valentine, 1999). Therefore, understanding parental views about teenagers' eating and any associated risks requires an approach that acknowledges the contested nature of risk; accesses lay theorising; and situates these understandings within meaningful biographical, structural and cultural contexts (Mitchell, Crawshaw, Bunton, \& Green, 2001; Duff, 2003).

Parents' views about their teenager's health and lifestyles must also be set in the context of their images of that young person, his/her age and lifestage, and against the background of the interactive nature of the socialization process (Christensen, 2004). Youth is often seen as a period of invulnerability by adults and young people themselves, when the body is least likely to succumb to illness and disease (Lawton, 2002) and 
activities like smoking, drinking and eating unhealthy foods are considered enjoyable and fun (Denscombe, 2001). Paradoxically, though, in the late modern age, adolescence and the protracted transition to adulthood may also be seen as a challenging time for young people. During this time they adapt to physical, emotional, economic and social changes and 'risky' health behaviours may offer some relief (Furlong \& Cartmel, 1997). Particularly during the early teenage years, parents themselves may face the challenge of balancing young people's increasing desire for autonomy with their own feelings of responsibility, control and protection.

This paper presents findings from a qualitative study in Scotland which examined the views and understandings underpinning the dietary practices in families with 'normal' weight and 'overweight' young teenagers living in poorer socio-economic circumstances. We report findings about parents' views and experiences drawn from this study in which 36 boys and girls aged 13-14 years and 34 of their parents/main food providers were interviewed in depth. Findings from our interviews with young teenagers have already been reported (- in press). In this paper we examine parents' views about their teenagers' tastes and eating behaviours and consider the meanings attached to eating at home and away from home. We then discuss some of the ways that parents contextualized teenagers' dietary habits, body size and shape within their own meaningful frames of reference. 


\section{Methodology and study design}

An iterative qualitative approach was adopted allowing the exploration of themes emerging during data collection in addition to those formulated at the study's outset (Britten, Jones, Murphy \& Stacy, 1995). As the research focussed on young peoples' and parents' conceptualizations of dietary practices, food choice and weight in the early teenage years, the sample of boys and girls was evenly divided into two categories, defined by their Body Mass Index (BMI) as normal weight or overweight/obese.

\section{Recruitment of Participants}

The sample comprised families living in socio-economically disadvantaged circumstances because young people living in such families are more likely to be overweight or obese (Armstrong \& Reilly, 2003). Following ethical approval from relevant education authorities, the research team visited three schools and several youth groups in areas within Eastern Scotland classified as socio-economically disadvantaged using the Breadline Britain Index (Gordon \& Forrest, 1995), a measure based on multiple measures of deprivation. Areas were located in semi-rural locations and small or medium sized towns. Double consent was sought: parents were asked to 'opt out' if they did not wish their child to participate; young people gave their own written consent. In the first phase the teenagers were interviewed in their homes. Subsequently, their parents were re-contacted to see if they themselves were still willing to be interviewed, their written 
consent was obtained and 34 out of 36 parents participated. Interviews were conducted with the parent whom teenagers had identified as being their main food provider.

\section{Data Collection}

At point of first contact, in schools or youth groups, teenagers were weighed and measured to ascertain their Body Mass Index $\left(\mathrm{BMI},\left(\mathrm{kg} / \mathrm{m}^{2}\right)\right.$. They also filled in a short screening questionnaire to collect a variety of socio-demographic data and information about physical activities; perceptions of their own body size; and details of favourite foods. The young people were selected on the basis of their gender, 18 girls and 18 boys; their BMI, 18 'normal' weight and 18 overweight or obese (classification for children informed by Cole, Bellizzi, Flegal \& Dietz, 2000); and their socio-demographic details (choosing those living in the most deprived postcode sectors and taking account of household composition, parental occupation/s and car use) (Wills et al, 2006).

The second phase of fieldwork, with the parents, was conducted shortly after their son/daughter had been interviewed. Interviews took place in their homes and lasted about one hour. The topic guide mirrored that used with the young people, drawing, in a generalized way, on emergent themes as well as relevant literature. Topics included: general information about parents' and their teenager's everyday and family lives; perceptions of health, food and eating, weight, body image and appearance for their teenager and themselves; notions about their own and their teenager's bodies and those of 
family and friends. Interviews took place between February 2003 and January 2004 and were tape-recorded with participants' consent.

\section{Data Analysis}

Interviews were transcribed verbatim and anonymised. Field notes were taken and interview summaries written to enable quick reference to the whole sample during more detailed analysis. Selected transcripts were read by all team members and discussed in team meetings to identify emergent themes. Notes were taken on these analytical team meetings and an emergent analytical framework developed from the themes identified. Data were then coded and retrieved using the qualitative data-indexing package, QSR NUD*IST. Detailed analysis of the parents' data set was carried out by reading and rereading cuts of the data, using manual and computer-aided indexing. All names used in this paper are pseudonyms.

\section{The sample families}

Reflecting the population as a whole, family structures were often complex. Half of the teenagers lived with both biological parents; a quarter lived in reconstituted families, many of these had no contact with their non-resident parent. Of the remaining quarter, 3 teenagers lived with their mother whilst 6 lived with grandparents (in one case their mother also lived there). Being resident with grandparents was because of family breakdown or estrangement; death of a parent; teenagers' health problems; overcrowding 
at home. Overall, about half the teenagers not living with their father had some contact with him; two did not see their biological mothers (one of whom had died). Approximately two thirds of the interviewees were mothers, several interviewees were grandmothers and only one father was interviewed. Nevertheless, given this family diversity, the majority of the themes discussed in the paper reflect the views of all of interviewees. Consequently, in the paper we use the term 'parents' throughout as the majority of young people were resident with their parents, even if, for a minority, a grandparent was interviewed as the 'main food provider'.

\title{
Findings
}

\section{Teenagers' food preferences and eating behaviours}

\section{Tastes and responsibilities}

\begin{abstract}
Almost all interviewees described the meals prepared at home as cooked by themselves. For many, then, 'home-made' meant meals prepared and served at home, and considered by parents to be 'good food'. However, their descriptions of typical meals showed that it was only in a minority of households that meals were prepared from scratch using basic ingredients; ready made foodstuffs were regularly used, with a particular reliance on preprepared bottled sauces. The main exception was the subsample of grandmothers whose descriptions showed that they chose to prepare more traditional meals (meat and two vegetables, basic ingredients). Almost all parents said that they tried to have a family
\end{abstract}


meal, sitting together, at some point in the week or weekend but, for most families, eating together on a more regular basis was described as secondary to the other demands, routines and activities in all of their lives. Although many interviewees said they prepared a daily meal for everyone, this might be eaten at different times and/or at the same time but in different parts of the house, particularly by the teenager.

In the majority of families there was a strong acknowledgement of individual tastes and preferences. Interviewees described in some detail what each child/young person they looked after liked and disliked to eat and it seemed to be accepted that, in general, such preferences should be accommodated. There was, for instance, little talk of insisting that children eat disliked foodstuffs even if, as was particularly the case with vegetables and sometimes fruit, these were also regarded by the majority of our adult sample as being 'good for them'. Interviewee11 admitted that 'Alec'll not venture past the banana'; Interviewee22, who felt that all of her children were 'pretty good eaters', went on to say that they were 'not big on vegetables'; and Interviewee35, who said that her son was a good eater and not fussy, responded to a probe about whether he ate vegetables as follows, 'not very much, I must admit, no, and I'm guilty o' that 'cause I dinnae really like vegetables. I suppose if I ate more vegetables, they would eat more'. Sometimes fruit and vegetable eating was described as just not fitting into their teenager's lifestyle, for example: 
'Maybe because if, I mean I could put oot carrot sticks and sticks o' pepper and cucumber. And she'll eat them if there werenae crisps to dip. So it's, I think it's just whatever's convenient. She can carry crisps wi' her'. (Interviewee2)

Although, when questioned directly, almost all parents said that healthy eating was important, nevertheless, the majority of our sample described their teenager's distaste for many of these 'healthier' foodstuffs in an unquestioning, taken-for-granted manner, as the following quotation illustrates:

'I wouldnae always say he eats the right things, just like most kids aboot here. $\mathrm{He}$ will rather go tae like McDonalds or a pizza or a chippy (fish and chip shop) than have Mum cookin' somethin' or... I always make sure his Sunday meal is a sit doon Sunday meal an' that's always like maybe chicken an' well roast beef an' ken [Scottish phrase meaning 'y'know'] like he always has his Sunday dinner. But at school... he doesnae eat very healthy at school, he always just has like chips an' [fizzy] juice an' a biscuit an', ken, so that's no' healthy. Em, I must admit I do try an' encourage him to eat fruit an' which he does now an' again, he does like his fruit'. (Interviewee28)

In a minority of families, their teenager's general dislike of 'healthy' foodstuffs was felt to be of some concern, but this was presented as largely because they were viewed as 'fussy eaters' and therefore as problematic to cater for. Often such parents were keen to explain that their other children were not fussy and ate a wider range of foods or, indeed, 
some 'healthy foods'. In some respects, therefore, this seemed to enable them to distance themselves from feeling responsible for the teenager who ate a poor diet. Similarly, some of those who described their offspring as 'good eaters' did so because the young person did not complain about and ate all of the food provided at home, rather than claiming that their teenager ate 'good' or 'healthy' foods. Interviewee15 said that her daughter was 'a good eater if you give her what she wants'. In the majority of such instances it was often the easiness of catering for those particular 'not fussy' teenagers that appeared to be valued by the parents.

It was also apparent that the food choice and eating practices of their young teenagers were increasingly viewed by many parents as the teenagers' own responsibility. Statements such 'at his age he'll eat what he wants to eat'(Interviewee 11) and 'I just leave him up to hisself' (Interviewee 6), reflected views expressed by most of the sample. One mother described, as follows, her difficulties in exercising control over her teenager's eating:

'I think for me, it's important for her going to school with even a bowl of cereal or a piece of fruit or something like that. But her appearance is more important and she'll maybe grab a packet of crisps going up the road, which is not, in my view it's not, it's no good enough, but what can I do? I mean I cannae force food down her neck'. (Interviewee20)

Several interviewees talked about their teenager's social and leisure activities taking precedence over what they might eat. One mother said: 'Robyn often cooks for herself 
because she never wants to eat at the same time as us. She's always got somebody on the phone or getting ready to go somewhere or she tends to have pasta, takes like five minutes to make' (Interviewee9). And another parent described this lightheartedly as follows: 'Alison and Gregory both like to come in, get changed, something to eat and away out with their friends, so, (Interviewer: so they don't like waiting around?) they don't like waiting around'. (Interviewee10).

In these respects, then, and as other studies have also shown (Fuller, 2002), convenience and snack foods offered one way of accommodating varied tastes simultaneously, coordinating schedules, keeping everyone happy and ensuring food was not wasted. The main exception to this was the sub sample of grandparent carers who, as indicated above, usually prepared only one set of food for the evening meal, though the teenager could still choose not to eat every item. For other parents, however, the need to make sure that the foods bought on a limited family budget were consumed by the teenager predominated over any expressed concern about the nature of the food s/he actually ate.

\section{Eating at home and away from home}

Overall, then, these interviewees presented a complex picture of trying to ensure that their teenager's tastes were catered for within the constraints of the young person's social life and his/her perceived increasing personal responsibility, as well as those of family budgets and parents' own work/leisure commitments. That this food was bought and usually prepared by the parent meant that they referred to it as 'home-made'. 
As in other studies (Lupton, 2004), it seemed that parents also held different opinions about foods consumed by the teenager in the home and outside the home, with the latter being portrayed as less healthy, more risky and often outwith parental control. Many said they did not know or could do little about what their teenager ate during the school day or when they were with their friends, with some feeling that, at least to a limited extent, this could be balanced out by what they ate at home. The following quotations are typical:

'If they have a-a crappy school meal then I'll make sure then that they're having something decent at night' (Interviewee8)

'I think David would probably have chips most days at school. And he's at the stage now that he won't come home and it's a stand up fight, so I mean I do think likes of David, although he doesn't eat very much in here that's bad, I think possibly he's havin' chips more often than not at school.' (Interviewee33)

Junk foods as risky foods

Most parents claimed, however, that, within the home, they tried to set some limits on the teenager's consumption of junk and snack foods and put this forward as one of the ways of trying to ensure a reasonably healthy diet. It was interesting that, although almost all 
interviewees expressed criticisms of junk foods, nevertheless these appeared to be viewed more negatively when consumed outside the home and outwith the parent's control. Some parents, such as the following mother, presented their efforts to control the eating of junk food at home as something of a losing battle, but they claimed, at least, to provide some healthy foods and to encourage the young person to eat them:

'Eh I've been trying to encourage him to eat fruit in the morning and fruit juice. Instead of fizzy juice. But given the chance he'd soon revert back to what he wants tae eat. Eh which, like the other day I caught him wi' six biscuits. He was gonna go oot the door wi' [it] but I didnae let him. Or he'd go out wi' crisps if he got away wi' it. Lazy. Very lazy when it comes to food. Whatever's at hand. Junk food that he likes.' (Interviewee6)

Overall, though, it seemed important for most parents to claim that their teenager had an 'O.K.' or satisfactory basic diet at home; 'fussy eaters' were seen to be at greater risk of having a poor diet, even though 'good eaters' were often also described as eating and enjoying less healthy foods. However, it was the additional junk/ snacks that were mainly seen as putting the teenage diet in jeopardy and risks of poor food choices were portrayed by parents as increasing when the young person was outwith the home. 


\section{Teenagers' eating and notions of risk}

\section{Hierarchies of risk and worry}

It is already evident then, that, in the course of providing food for their teenagers, these families were negotiating potentially difficult terrains of teenager taste, personal choice, increasing autonomy and perceived risk. However, when considering these parents' views of their teenagers' diets, it is important to ground such accounts in the context of how they assessed other kinds of risks that their teenager might encounter. This was shown in the ways that many interviewees readily discussed their teenagers' lives more generally and any problems that they were seen to be facing. A few teenagers had had difficult family circumstances or experiences to deal with, which had sometimes led to the grandparents becoming the main carers. One boy, whom his mother described as settled and confident, had lost his father and much loved grandfather in the space of two years, during which time he also started secondary school. Against this background, unsurprisingly, his mother was relatively unconcerned about his being overweight and said:

'I don't think his weight... Lawrence is what he is an' I don't think his weight issue does bother... He's never spoke ti me aboot it. He's never actually sat doon an' said “Ken Mum, I hate bein' like this". (Interviewee28). 
Even if there were no such serious worries, for the majority of parents it was apparent that concerns about what their teenagers ate were quite far down the list in their hierarchies of current or potential worries about them and the risks or dangers they faced. For example, interviewees expressed relief if their teenager had friends, did activities outwith the home, was not being bullied or doing badly at school, and was not mixing with a bad crowd. Equally, when thinking about potentially health damaging issues, dietary concerns seemed of little importance to these parents compared with the risks they perceived as associated with drugs, smoking, alcohol and sex, for example:

'So it's no' so much the food-wise I dinnae think, it's the smoking an' the drugs an' the drink-wise that's mair worrying than the food, ken, what he's eating. An' running aboot wi' the wrong crowd is worrying but you just have to try an' impart wisdom. Mind you they dinnae always listen though, that's it. Even about food, you'll say “It's good for you” you know, 'No, I'm no' eatin' that".' (Interviewee30)

Perceptions of teenagers' food choice, 'fatness' and risk

Although food choices and eating practices seemed, then, to be given a fairly low priority in the hierarchy of 'risky' early teenage health-relevant behaviours (many of which were increasingly out of sight from them), parents were able to tell us in considerable detail about what they could see, their body sizes and shapes. Half of the sample teenagers had BMIs in the overweight or obese categories, half were normal weight. However, given 
that neither the parent nor teenager had been told their BMI, it was interesting that only when interviewees themselves described their teenager as 'very fat indeed', or as having a definite weight problem, did this frame any discussion of the problematical nature of their food choice and eating practises. Indeed, several parents of normal weight teenagers gave almost equivalent descriptions of their 'fussy' behaviours or 'junkoriented' tastes to those given by parents of overweight teenagers. However, these were not presented as particularly problematical or risky because, in other respects, their teenager 'looked' healthy to them (i.e. s/he appeared to be slim). For example, one mother, who was relatively unconcerned about her chocolate-eating son, said:

'But no, I mean Jason just... he could eat like a pig an' he just doesnae put on any weight at all. So I don't know, I don't see how... I mean he eats a lot mair fatty stuff than I do’. (Interviewee27)

A striking finding from the parents' interviews was that, like their teenagers, the majority did not express any great concern about the young person's weight or overweight and, with one or two exceptions, emphatically did not feel that s/he should go on a weight reducing diet. For instance, Interviewee15 said she would not speak to her daughter about being overweight in case this might, 'maybe give her a problem later on in her life, make her too conscious at a young age and maybe not be able to handle that information'. However, most of the sample expressed much greater concern about any preoccupations with becoming too thin, for example: 
'I mean likes of, they either... adolescents tend to either go really tall and gangly without any shape whatsoever which one of his friends is like, I mean the stick insect really, honest to goodness, he is. And then David is the opposite end of the spectrum where he's quite chunky. And I think likes of... no... I don't believe in making children obsessive wi' their weight, because I think that causes problems too. I mean if you keep saying "Oh you shouldnae eat this, you shouldnae eat that 'cause you're too fat" or... you gie (give) them an inferiority complex and they think... you can get problems there as well, 'cause I know a girl that that happened to, she went anorexic'. (Interviewee33)

The majority of parents said they were much more likely to emphasise to their child that weight should not be a worry or concern for them; that they were fine as they were; that everybody was different; and, frequently, as above, to make disparaging references to their thinner peers as 'stick insects' (a much used phrase). In these respects, although sometimes saying that they did actually think their teenager was 'a bit too fat' at present, parental accounts indicated a desire to bolster their offspring's self esteem and positive body image when speaking to the teenager him/herself. On balance, therefore, it seemed that these interviewees felt that issues around weight in the early teenage years were less potentially problematic than the risks to their mental or physical health of becoming obsessed with weight loss. The only advice many reported giving to their teenager (whether they saw them as overweight or not) was to cut down on junk food (e.g. crisps, sweets and fizzy drinks). It was not the case that these parents expressed no concern about their teenagers' weight, rather, at the teenager's current age, most seemed to feel 
that an over-concern might be counter-productive. Typical in this respect was the mother who said that, 'I'm no' wanting to get intae her head that she's fat' (P5), but that it would concern her if her daughter started to get any bigger.

\section{Families, inheritance and the mysteries of body size.}

It was apparent that, in many of these families, just as there was an acceptance of a variety of eating patterns and tastes, so parents also identified within their family a range of body shapes and degrees of thinness and fatness. Moreover, family members' bodies were often described as having changed over the years. One grandmother observed of her grandson: 'he's never really been that fat but, as I say, he was a wee bit obese for his age at times, but you couldnae really put a finger on why, whether it was just his age or what, you know' (Interviewee31). Some described their teenager as always having been thin or big, others had observed him/her to change in shape and size at different times in their lives. Interestingly, each of these conceptualisations tended to be put forward as supporting a non interventionist strategy where weight was concerned. For instance, one mother said:

'I think it was just puppy fat. I wasnae concerned because she wasnae eating junk food all the time. I think it was just her age. Sometimes when they get to that age they put weight on and then they lose it. My young sister was like that when she was a teenager. She put quite a lot of weight on and then she went thin. I thought 
she was maybe just going to be like her cause she reminds me of my sister a lot.' (Interviewee12)

So, a conceptualisation of diverse and changeable body types and shapes, often presented in a taken-for-granted fashion, also formed the backdrop to how parents made sense of the potential risks of teenagers' food choices and weight. As is evident from the above quotation, understandings of the sample teenager's body size and shape were also contextualized within descriptions of other members of their nuclear family (particularly the teenager's sibling(s)) and notions of wider familial inheritance. In some ways, such understandings of shape and size could be seen as counterbalancing ideas of teenage responsibility for the potentially risky embodied consequences of their food choices since they were spoken of with an air of inevitability. For example, parents often compared and contrasted bodily differences between their offspring, frequently referring to these in terms of their 'build'. Like the following mother, many also identified differences which led them to expect that one child might be fatter than the other(s):

'He's built like his dad eh, Mick's six foot two and aye been like sorta skinny. Whereas Robert's gonna be the same (son). He's no skinny but he's just fine. (Interviewer: And what about Sadie (daughter) does she put on weight or?) She could put on weight, aye'. (Interviewee8).

For the majority of this sample, then, a further way of making sense of their teenager's weight and body shape and whether this was felt to be risky was in terms of who they 
'took after'. Such sense-making work has been described as characteristic of a wider lay epidemiology (Davison, Smith \& Frankel, 1991) and, for these parents, this could be seen as, again, providing a legitimation of a strategy of non interventionism with regard to their teenager. After all, just as with the lay epidemiological observation of 'Uncle Norman who did everything wrong and lived to the age of 90' so, for every overweight teenager in their family, most of these parents readily identified others (sometimes their other children) who ate much more (and more junk) and never put on any weight. Those who perceived their teenager as being naturally slim readily attributed this to 'taking after' a parent or other family member.

All of those parents who described their teenager as a 'bit fat' were readily able to identify a close family member of similar shape and, indeed, in the majority of these cases a large part of the interview subsequently concerned the mother's own problems with overweight, as we go on to discuss later in the paper. There was a definite feeling of inevitability in the way that many of these views were expressed, combined with a sense that such inheritance was hard to alter through personal behaviour change. For example one woman said: 'and I've never been skinny. [My family] are no skinny women, my sisters are no skinny I don't think there's much chance of ever being skinny!' (Interviewee5) 
The lifecourse: eating, age and risk.

It is apparent from these findings that parents held culturally-based ideas about the appropriateness of the eating behaviours and body size of their young teenager. Some of these ideas, such as allowing them to have their own tastes and food preferences; accepting that they would eat differently in a variety of social situations; being concerned about faddy weight- reducing diets; and acknowledging the variety of body types in families and inherited traits, could be seen as views and understandings that spanned all ages and lifecourse stages. However, when interviewees talked in some detail about their own eating behaviours and their own problems with overweight, a further range of understandings were put forward. These demonstrated that they contextualised their teenager's eating and weight (whether s/he was currently slim or overweight) within quite different lifecourse and experientially based frames of reference.

If, as claimed above, fatness in the early teens was not seen as risky, the comparisons many made with the teenager's older siblings and with themselves nevertheless showed concern about what might happen in the years to come. Two thirds of the parents in this sample identified themselves as overweight. In addition, some said that their older offspring might now be overweight/obese and dieting, whilst others expressed some worry that the parent or relative whom they saw as of similar slim build, or 'looking like', the sample teenager had subsequently become overweight. As one parent said of her teenager: 'she's the type that, when I was her age, I was like that. I could eat anything, I never put the weight on and then all of a sudden I really piled it on' (Interviewee3). 
Thus, the data clearly showed that these interviewees were very aware of overweight in themselves or their families at later points in the lifecourse.

Paradoxically, however, and despite this awareness, the discourse of acceptance of the early teenager's body shape and size, combined with a certain resignation about teenagers' lifestyles, autonomy and eating patterns appeared to militate against what the Interviewer referred to in her fieldnotes as any 'amber lights' going on regarding overweight or unhealthy eating in the sample teenager. However, analysis of the wider data where many interviewees spoke at length (often unsolicited) about their own eating and weight suggested further understandings of this paradox. When talking about these issues, most parents' understandings of eating behaviour and weight were meaningfully located within their own personal experiences or within the worlds of adult concerns. Few, for instance, spoke of having been overweight themselves as teenagers; for most, weight gain was described as having come in adulthood. The following quotation was typical and illustrates the extent to which fatness in the early teenage years was not an issue with which many of our sample personally identified:

'I didnae have a weight problem even though I ate loads and loads of biscuits and everything when I first got married, I didnae have a weight problem until about ten years later or something like that'. (Interviewee2)

Although the parents' interviews also focused on the contribution of junk food to increasing their own weight, again this was in the context of their lifestyles as adults. For 
most, there was little mention of their having eaten junk or particularly fattening foods as young teenagers themselves; this tended to be seen as a more recent issue. Consequently, any reported advice to the teenager seemed to be couched in the language of the adult world of dieting (cut out fatty and junk foods, substitute fruit, watch calories etc.), which may, or may not, be salient to a young teenager's social and food worlds. Moreover, all but one of the interviewees were women (although some fathers and grandfathers did offer comments if present when the interview took place) and a range of gendered understandings were put forward. Some spoke of hormonal changes, many claiming that they had put on weight when they had children. In all of these ways, therefore, there seemed not to be an acceptable discourse to make sense of issues of overweight or risks of unhealthy food choices or over eating in early teenagers, apart from blaming junk food.

\section{Discussion and Conclusions}

In this paper we presented the views and experiences of parents/main food providers living in social disadvantage concerning their early teenage children's dietary practices. Importantly, these interviewees appeared largely to accept that, within the constraints of foods provided at home, their early teenagers could make their own dietary choices. They felt they had much less influence outwith the home where choices were seen as, increasingly, the teenager's own responsibility. It was the unusual parent who monitored what their young teenager ate outwith the home, or, indeed, seemed to view this as a 
concern. In many respects, therefore, the challenge for public health may not be simply to engage parents with the issue of addressing adolescent food choice but rather to acknowledge and work with the wider social, media and community influences on teenage behaviour.

There must, however, also be a realistic and up-to-date appreciation of what is happening in the home and the wider challenges facing families. As in other studies, it appeared to be the exception rather than the rule for times, places and contents of meals or snacks to coincide for the sample parents and their teenagers on any kind of regular basis and, indeed, that parental influences could be indirect and subtle (Eldridge \& Murcott, 2000). We found that parental influence was mediated through, for example, economics and economising; values and attitudes underpinning everyday reactions and negotiations within families ('fussy' and 'good' eaters); parents' own behaviours and example. Our study goes further than this, however, and shows that their teenagers' eating behaviours were not the most pressing concerns expressed by this predominantly low income sample. Food choices and eating practices seemed to be given a fairly low priority in the hierarchy of 'risky' early teenage health-relevant and social behaviours. The reasons for this are complex and may resonate with general work on negotiations between young teenagers and parents (e.g. Solomon et al., 2002; Eckert, 2004). For instance, the early teenage years could be seen as a liminal stage between childhood and adulthood when young people's own developing tastes and choices have to be acknowledged; their social worlds, with associated risks and dangers, may be expanding; and many are becoming more autonomous and independent of their parents. 
Importantly, though, such challenges and worries about their teenagers and their futures may be exacerbated when parents, such as those in this study, are living in disadvantaged circumstances, have fewer resources at their disposal, and are raising their children in potentially less safe environments. We have presented qualitative data about families living in social disadvantage but greater understanding is still needed about the everyday experiences of feeding families in other social groupings, to illuminate differences and commonalities in the population as a whole. Public health interventions need to engage with social class differences that not only underpin perceptions of health, diet, weight and the body but also structure the everyday contexts in which these are meaningfully understood.

Our interviewees demonstrated a keen awareness of the many issues and uncertainties also facing their teenage offspring. It is perhaps unsurprising, therefore, that they seemed more concerned about their children's emotional well-being than they were in drawing the young person's attention too much to unhealthy foods or weight gain, especially since there remains a general feeling of bodily invulnerability at this young life-stage (Backett and Davison 1993). It is not that these matters were unimportant to these parents, they were simply viewed as less important than other worries about children at this particular age. 
Health-relevant issues, such as teenagers' weight and dietary practices, may therefore mean different things to, and be accorded varying levels of salience by various population groups. This may also be the case along other dimensions, such as age, lifecourse stage and gender. Public health and health promotion must engage with these potential variations and work to understand the underlying meanings and differing priorities. Our interviewees offered a wide array of genetic, contextual and behavioural understandings of their early teenager's body size and shape, familial inheritance being only one of many parental explanations (Hunt, Emslie \& Watt, 2000). Further, trying to explain the differences they identified between the sizes and shapes of their offspring also led several parents to feel that these could not simply be attributed to what they provided for them to eat at home. Rather, parents tended to make sense of such differences with reference, for example, to the additional (junk) foods a particular child consumed; the stage of growing that s/he was at; or their own adult weight problems. In addition, though, our sample seemed to lack repertoires of understanding of overweight or unhealthy eating that were salient to the early teenagers' own worlds of meaning. It seemed that, when these parents and grandparents reflected on the weight and dietary practices of their teenagers, there was no directly comparable template from their own childhoods on which to draw. All of these understandings and meanings appeared to hold this sample of parents back from any active engagement with early teenagers' food choices, dietary practices or weight management.

In reaching these conclusions, however, it is also important that these qualitative interviews be reflexively understood as accounts of parental practices. Health and dietary 
practices are moral domains. Hence, it is likely that interviewees were not just talking about their children's food choice and eating behaviours, they were also explaining and accounting for their own roles as parents and food providers. Indeed it may not be coincidental that interviewees seldom spoke of themselves as offering unhealthy or 'bad' foods to their teenagers. Rather, they emphasised their own control over junk foods in the home and distanced themselves, often somewhat helplessly, from the teenagers' own tastes and choices outwith the home. In these respects, it is important for health promoters to appreciate that, in order to present a positive picture of themselves and also because food is only one element of complex adult-child negotiations in families, parents may not fully acknowledge their own part in teenagers' food choices.

It is important to understand the ways in which parents make sense of their teenagers' eating and weight and the socio-cultural contexts in which they are embedded because preventative health interventions are more likely to be successful if they resonate with the lay perspectives and everyday experiences of their intended audiences (Milburn, 1996). Moreover, these parents' views are not stand alone entities; because health is interactive and pluralistic, their offspring also create meanings for themselves (Wills et al, 2006). Indeed, 'parents may now be seen as very important mediators in children's health actions rather than being seen as having the main direct influence upon them'(Christensen, 2004). Current social concern about young people's weight and diets must take parents' views into account but also locate these issues in wider debates about teenage transitions to adulthood; perceptions of health-relevant risk; and food policy and the politics of food. 


\section{References}

Armstrong, J., \& Reilly, J.J. (2003). The prevalence of obesity and undernutrition in Scottish children: Growth monitoring within the child health surveillance programme. Scottish Medical Journal 48, 32-37.

Backett, K., \& Davison, C. (1995). Lifestyle and lifecourse: The social and cultural location of health behaviours. Social science and Medicine 40, 629-638.

Backett-Milburn, K., \& Mackinnon, D. (Eds) (2003). Young people's health and wellbeing. Scottish Youth Issues Journal, Special Edition 6.

Backett-Milburn, K., \& Harden, J. (2004). How children and their families construct and negotiate risk, safety and danger. Childhood 11(4), 429-447.

Brannen, J., Dodd, K., Oakley, A., \& Storey, P. (1994). Young people, health and family life. Buckingham and Philadelphia: Open University Press.

Britten, N., Jones, R., Murphy, E., \& Stacy, R. (1995). Qualitative research methods in general practice. Family Practice 12(1), 104-14. 
Boutelle, K.N., Lytle, L.A., Murray, D.M., Birnbaum, A.S. \& Story, M. (2001).

Perceptions of the family mealtime environment and adolescent mealtime behaviour: Do adults and adolescents agree? Journal of Nutrition Education 33(3), 128-133.

Cole, T., Bellizzi, M., Flegal, K., \& Dietz, W. (2000). Establishing a standard definition for child overweight and obesity worldwide: international survey. British Medical Journal 320, 1-6.

Charles, N., \& Kerr, M. (1988). Women, Food and Families. Manchester: Manchester University Press.

Christensen, P.H. (2004). The health promoting family: A conceptual framework for future research. Social Science and Medicine 59(2), 377-387.

Davison, C., Smith, G. D., \& Frankel, S. (1991) Lay epidemiology and the preventions paradox: The implications of coronary candidacy for health education. Sociology of Health and Illness 13, 1- 19.

Denscombe, M. (2001). Uncertain identities and health-risking behaviour: the case of young people and smoking in late modernity. British Journal of Sociology 52(1), 157177. 
Dietz, W. (2001) The obesity epidemic in young children. British Medical Journa. 322, 313-314.

Dixey, R., Sahota, P., Atwal, S., \& Turner, A. (2001). "Ha ha , you're fat, we're strong"; a qualitative study of boys' and girls' perceptions of fatness, thinness, social pressures and health using focus groups. Health Education 101(5), 206-216.

Duff, C. (2003). The importance of culture and context: rethinking risk and risk management in young drug using populations. Health, Risk and Society 5(3), 285-299.

Eldridge, J. \& Murcott, A. (2000) Adolescents' dietary habits and attitudes: unpacking the 'problem' of (parental) influence. Health 4(1), 25-49

Frost, L. (2001). Young Women and the Body: A Feminist Sociology. Basingstoke: Palgrave.

Fuller, T. L. (2002). 'Healthy eating': Lay and professional perspectives in Scotland. Unpublished PhD thesis, University of Edinburgh.

Giddens, A. (1991). Modernity and self-identity: Self and society in the late modern age. Cambridge: Polity. 
Gillman, M. W., Rifas-Shiman, S. L., Frazier, A. L., Rockett, H. R. H., Camargo, C. A., Field, A. E., Berkey, C. S., \& Colditz, G. A. (2000). Family dinner and diet quality among older children and adolescents. Archives of Family Medicine 9(3), 235-240.

Gordon, D., \& Forrest, R. (1995). People and Places volume II: Social and economic distinctions in England - A 1991 Census Atlas. Bristol: SAUS Publications and the Statistical Monitoring Unit.

Green, J. (1997). Risk and misfortune: The social construction of accidents. London: UCL Press.

Henderson, L., Gregory, J. \& Swann, G. (2002). The national diet and nutrition survey: Adults aged 19-64 years. London: The Stationery Office.

Hunt, K., Emslie, C., \& Watt, G. (2000). Barriers rooted in biography: How interpretations of family patterns of heart disease and early life experiences may undermine behavioural changes in mid-life. In H.Graham (Ed) Understanding Health Inequalities. Buckingham: Open University Press.

Inchley, J.\& Currie., C. (2003). Promoting healthy eating in schools using a health promoting schools approach. Final report of the health eating project. Edinburgh: Child and Adolescent Health Research Unit, University of Edinburgh. 
Lawton, J. (2002). Colonising the future: Temporal perceptions and health-relevant behaviours across the adult lifecourse. Sociology of Health and Illness 24(6), 714-733.

Le Bigot Macaux, A. (2001). Eat to live or live to eat? Do parents and children agree? Public Health Nutrition 4(1A), 141-146.

Lupton, D. (2004), 'A grim health future': Food risks in the Sydney press. Health, Risk and Society 6(2), 187-200.

McCarthy, H.D., Ellis, S. \& Cole, T. (2003). Central overweight and obesity in British youth aged 11-16 years: cross sectional surveys of waist circumference. British Medical Journal 326, 624-628.

Milburn, K. ( 1996). The importance of lay theorising for health promotion research and practice. Health Promotion International 11(1), 41-46.

Mitchell, W.A., Crawshaw, P., Bunton, R., \& Green, E. E. (2001). Situating young people's experiences of risk and identity. Health, Risk and Society 217-228.

Murcott, A. (1987). Feeding the children. Journal of Education Policy 2(3), 245-252. 
Neumark-Sztainer, D., Hannan, P. J., Story, M., Croll, J., \& Perry, C. (2003). Family meal patterns: associations with sociodemographic characteristics and improved dietary intake among adolescents. Journal of the American Dietetic Association 103(3), 317-322.

Shaw, A., McMunn, A., \& Field, J. (2000). The Scottish Health Survey 1998. London: Joint Health Surveys Unit.

Sweeting, H., Anderson, A., \& West, P. (1994). Socio-demographic correlates of dietary habits in mid to late adolescence. European Journal of Clinical Nutrition 48, 736-748.

Sweeting, H. \& West, P. (2005).Dietary habits and children's family lives. Journal of Human Nutrition and Dietetics 18, 93-97.

Valentine, G. (1999). Eating in: Home, consumption and identity. The Sociological Review 47(3), 491-524.

Wills, W., Backett-Milburn, K., Gregory, S., \& Lawton, J. (2006). Young teenagers’ perceptions of their own and others' bodies: A qualitative study of obese, overweight and 'normal' weight young people in Scotland. Social Science \& Medicine 62, 396-406.

Wright, C., Parker, L., Lamont, D. \& Craft, A. (2001). Implications of childhood obesity for adult health: findings from thousand families cohort study. British Medical Journal $323,1280-1284$. 